\title{
Design and Implementation of an Aquaculture Response Device
}

\author{
Oke Alice O. \\ Computer Engineering \\ Dept. \\ LAUTECH Ogbomoso, \\ Oyo State Nigeria
}

\author{
Abolade Olatilewa R. \\ Computer Engineering \\ Dept. \\ Olabisi Onabanjo Uni.Ago- \\ iwoye, \\ Ogun State Nigeria
}

\author{
Jagun Zaid $O$. \\ Computer Engrg Dept. \\ Olabisi Onabanjo Uni.Ago- \\ iwoye, \\ Ogun State Nigeria
}

\author{
Adegbola Oluwole A. \\ Electronic and Electrical \\ Engineering Dept. \\ LAUTECH Ogbomoso, \\ Oyo State Nigeria
}

\begin{abstract}
In this paper, an aquaculture response device was designed and implemented. The impact of aquatic organism especially Fish cannot be over emphasized. Fish serves as one of the main sources of protein which helps in body building and the art of fishing is also a lucrative means of living. Various fishing techniques that have been employed such as angling, netting, hand gathering, trapping have not been an easy task due to the risks involved as it takes place mostly on a large volume of water surface coupled with dangerous marine organism that could be encountered. The design was achieved by the use of high continuous buzzing ultrasonic sound with appropriate output frequency to attract fishes, ESP8266 Wi-Fi Module, ATmega 328 microcontroller and other components. The developed device has ease of operation and aimed at automating fishing thereby bringing about modernized fishing practices, with economic importance of assisting fish farmers in attracting more fishes to increase income.
\end{abstract}

\section{General Terms}

Hardware design and control, Agriculture.

\section{Keywords}

Aquaculture response device, Fish pond, Fish caller, ATmega 328, ESP8266 Wi-Fi Module, GSM Module.

\section{INTRODUCTION}

Aquatic animals (especially freshwater animals) are subject to pressure from overfishing, destructive fishing, marine pollution and climate change. Examples are fish, mammals (whales), mollusks (sea snails), cnidarians (jellyfish), crustaceans (crabs). Fish farming which is also known as pisciculture is one of the ancient jobs of mankind that involves raising fish commercially usually for food. Demand is increasing for fish and fish protein which has resulted in widespread overfishing in wild fisheries (Au and Hasting, 2008). According to Food and agricultural Organization (FAO), Nigeria was one of the countries classified as a food deficient country; it is not therefore a surprise that Nigeria is rated low in terms of Human Development Index (HDI), [14]. This paper therefore designed and implemented a response device that can attract fishes without any risk using latest technology. Since Fish is nutritious and is one of the main sources of protein which helps in body building, mostly recommended for most adults rather than meat.

Several fishing techniques are available for fishing like the hook and line (angling), netting, hand gathering, spear fishing and trapping $[5,2]$. Several works had been done in this area among which are: the development of a fishing lure that emitted signals of different frequencies for the attraction of fish of particular specie [12]. The lure employed a piezo electric transducer driven by integrated circuit oscillators adjustable which produced various frequencies in a range from $1 \mathrm{KHZ}$ to $100 \mathrm{KHZ}$ by changing of circuit components. A sonic fishing lure was also developed for which a pair of astable multivibrators was employed which produced underwater sounds. $1 \mathrm{HZ}$ and $100 \mathrm{HZ}$ multivibrator were used together to provide intermittently pulsed outputs at approximately $100 \mathrm{HZ}$ [4]. A detector for fishing in order to detect the depth of water, the temperature of water, the distribution of fishes including fish's migration and/or the length of fishes was another development. These were achieved by the use of a sensor transmitting an ultrasonic signal into the water at the fishing site and receiving a reflective ultrasonic signal from an underwater object control unit and displayed using a predetermined program on a personal portable communications terminal like a mobile telephone [6]. Matthew and Corry [7] in 2012 discovered that human structures such as hydroelectric facilities often impede fish migrations and may inflict heavy mortality on fish that become impinged or entrained. More than 30,000 species of fish, ranging in length from $10 \mathrm{~m}$ long whale sharks to $1 \mathrm{~cm}$ carps was discovered in existence and there is a huge range in specializations and morphological adaptations [10,9].

Danos and Danos [13] in 2015 invented an aqua organism response device known as "fish call". It is a device that produced a continuous buzzing ultrasonic sound adaptedly disposed above water. The sound attracted fishes and other marine animals thinking its food. It is one of the easiest and efficient ways of fishing because scientists and biologists have found out that fish (and other marine animals) communicate with sounds [11, 8]. Aquatic organisms have a way of communicating dangers and basic responses through sound. The device used ultrasound and vibration technology to motivate nearby fish to school and bite more aggressively. Cutting edge hydrophone and computer technology were used to record the sounds and vibrations of a school of feeding fish. The recorded sounds and vibrations were then broadcast into the surrounding water to attract the fishes. This work is built on [13] with improvement in the area of how it is powered through SMS, internet using the Wi-Fi as well as manually, these can be used for a wide range of fish attraction. Its automated ability makes it different from the previous technologies as reviewed above.

\section{MATERIALS AND METHODS 2.1 Device Design}

The aquaculture response device comprised of electronic circuits designed to help attract fishes from sound. The design makes use of intelligent system for optimum efficiency which 
is divided into six (6) units which are power supply, ATmega 328 microcontroller, fish caller, GSM module, Wi Fi module and water surface as shown in Fig. 1.

\subsection{Power Supply Unit}

DC power supply supplies constant DC voltage to its load. A $9 \mathrm{~V}$ battery is the DC source of energy that was used for this work, it supplied power to the device this is as shown in Fig 2.

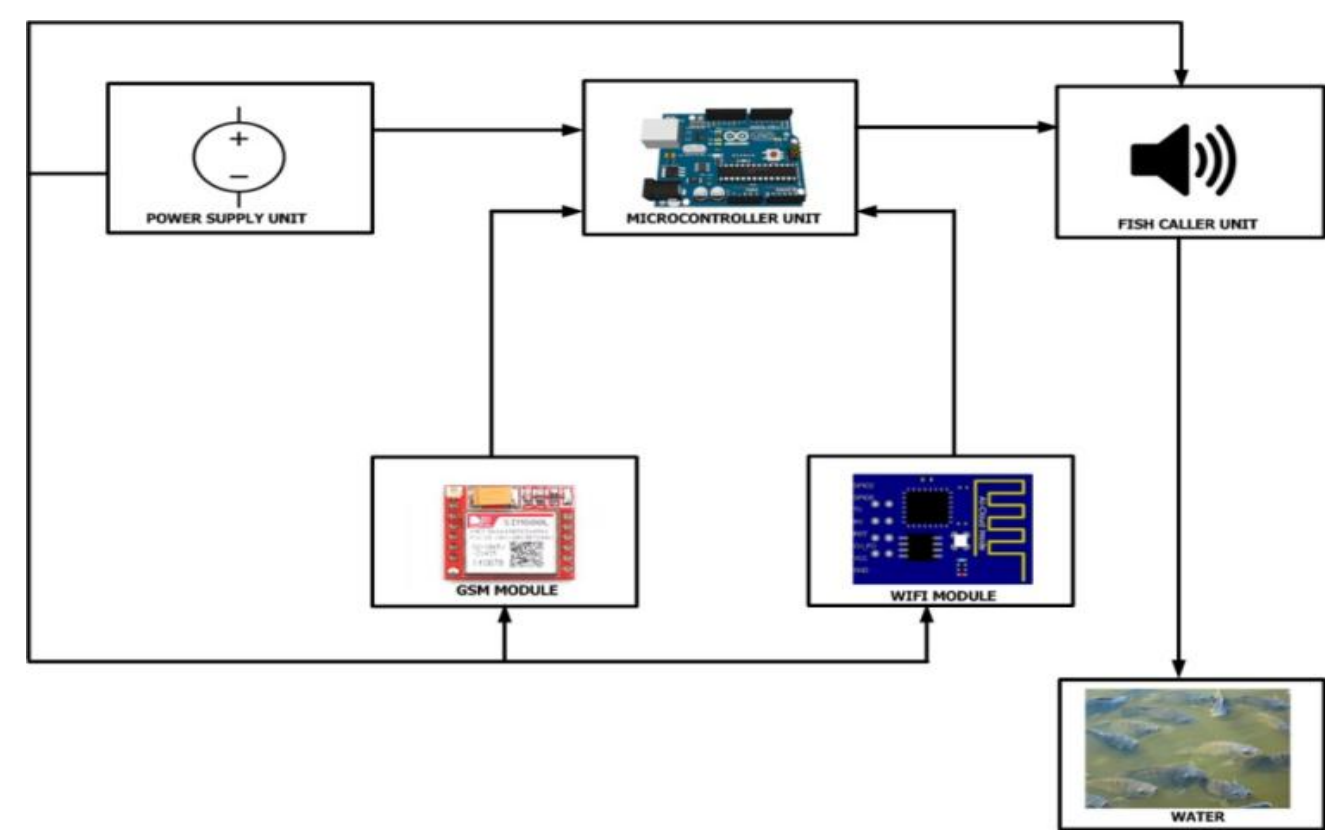

Fig. 1: Block Diagram of Aquaculture Response Device

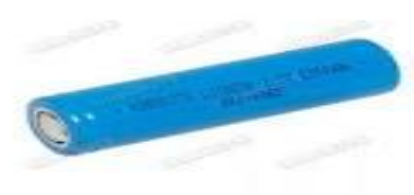

Fig. 2: Battery

\subsection{Microcontroller Unit}

The microcontroller used is the ATmega 328 which is an advanced Visual RISC (AVR). It supports data up to 8 bit. It also has $32 \mathrm{~kb}$ internal built in memory. This microcontroller has a lot of characteristics like 1kb Electrically Erasable Programmable Read Only Memory (EEPROM). It also has $2 \mathrm{~kb}$ Static Random Access Memory (SRAM). It has good performance as it processes 20 Million Instruction Per Second (MIPS) at maximum operating frequency of $20 \mathrm{MHz}$, low power consumption, it is a 28 Dual Inline Package (DIP) with maximum of 23 input/output pins including 2 external interrupts. Two ATmega 328 were used because of its Programming ease for both the GSM and Wi-Fi Modules Fig 3 shows the Pin Configurations of the ATmega 328 Microcontroller. The Microcontroller interconnects with the Fish Caller, GSM Module and Wi-Fi Units.

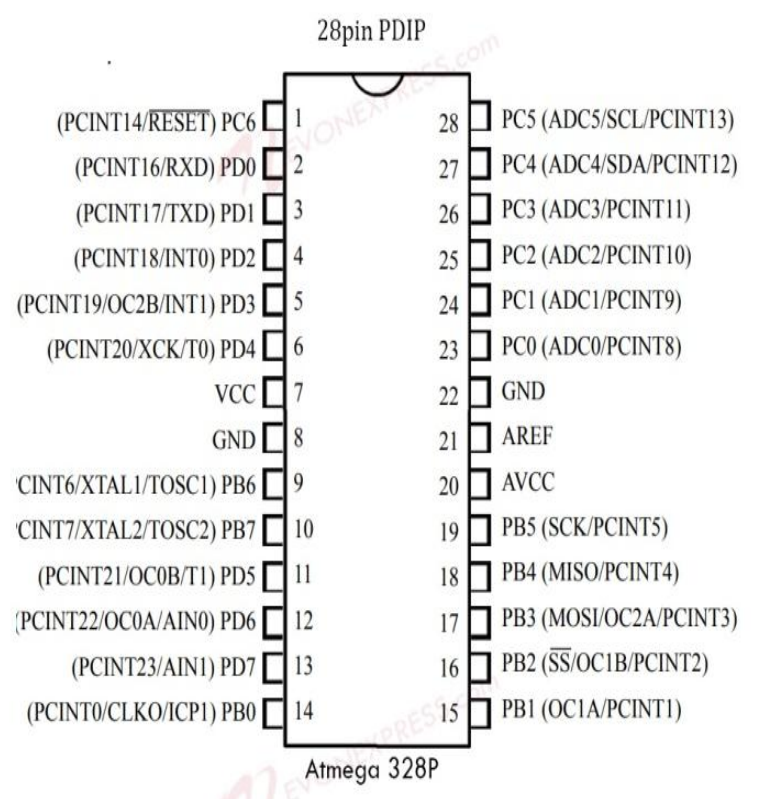

Fig. 3: ATmega 328 Microcontroller pin Configuration

\subsection{Fish Caller Unit}

This is the unit consisting of passive and active elements combined together to form the circuit. Some of these elements are resistors, capacitors, switch, 555 Timer, speaker. The speaker brings out sounds and vibrations from the device into the surrounding water to attract fishes and other marine animals. The major function of the fish caller unit is for fish attraction and the frequency range for fish response is 900 $1800 \mathrm{~Hz}$. Fig 4 shows the Circuit Diagram of the Fish caller Unit. In this work, a frequency of $1623.4 \mathrm{~Hz}$ was calculated using the 555 timer to give a continuous sound for fish 
attraction which falls within the range of fish response. From the Circuit diagram of the fish caller

$\mathrm{R}=56 \mathrm{k}, \mathrm{C}=10 \mathrm{nF}$

From the Frequency Formula
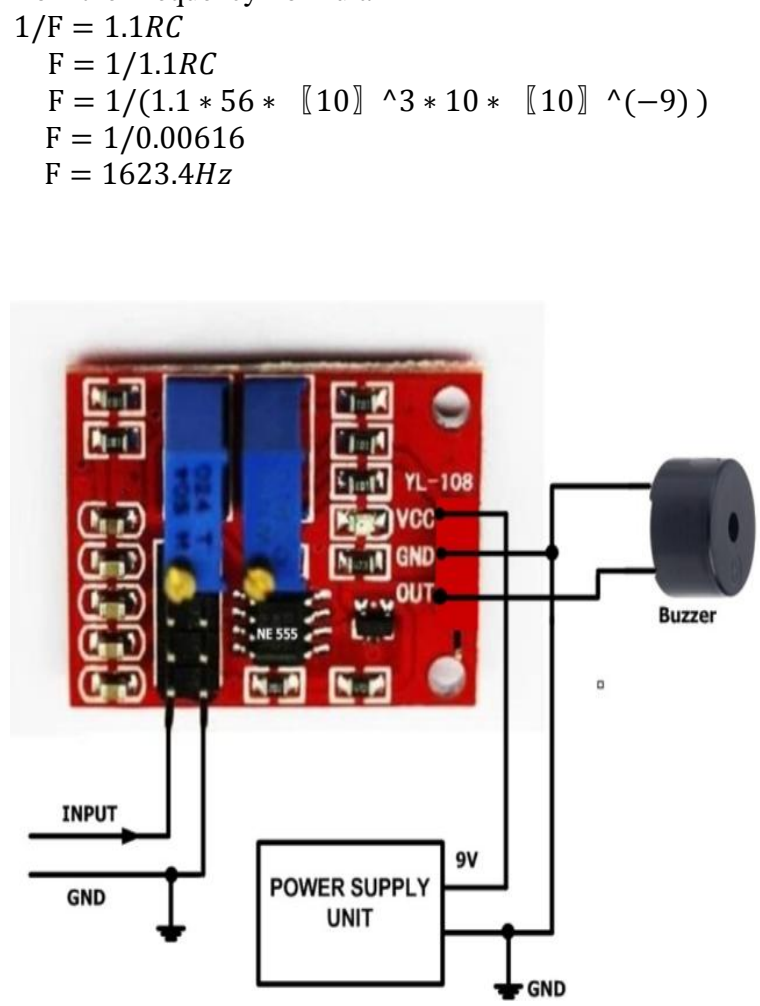

Fig. 4: Circuit Diagram of the Fish Caller Unit

\subsection{Global System for Mobile \\ Communication (GSM) Module Unit}

The GSM module is SIM800L which is a miniature cellular module that allows for General Packet Radio Service (GPRS) transmission, sending and receiving Short Message Service (SMS), making, receiving Voice note and calls. The GSM Module SIM 800L is used to power the device over a wide range of distance for automation. Low cost and small foot print and quad band frequency support make this module perfect solution for any device that requires large range connectivity. Other types of GSM module is the SIM 900L. This module has two antennas first is made up of wire while the second is the Printed Circuit Board (PCB) antenna. The GSM Module is shown in Fig 5.

The device was programmed using C Language which is an extremely popular, simple and flexible language which is machine independent, structured programming language and used extensively in various applications with Arduino. C Language is used in embedded systems, IOT applications, and complier production. A mobile number was attached to the Device for the efficient sending and receiving of SMS for Sound activation. A text message was programmed with the command ONE\$ for power ON and TWO\$ for power OFF to automate the device and activate the sound. An extract of the GSM module programme for the activation of the text message is as shown.

Serial.print("MessaageFrom: ");

Serial.println(number);

Serial.print("Content: ");

Serial.println(msg); if $($ msg.compareTo("ONE\$") == 0) \{

Serial.print("On fish caller");

digitalWrite(caller, HIGH);

else if $($ msg.compareTo("TWO\$") == 0)

Serial.print("OFF fish caller"); digitalWrite(caller, LOW);

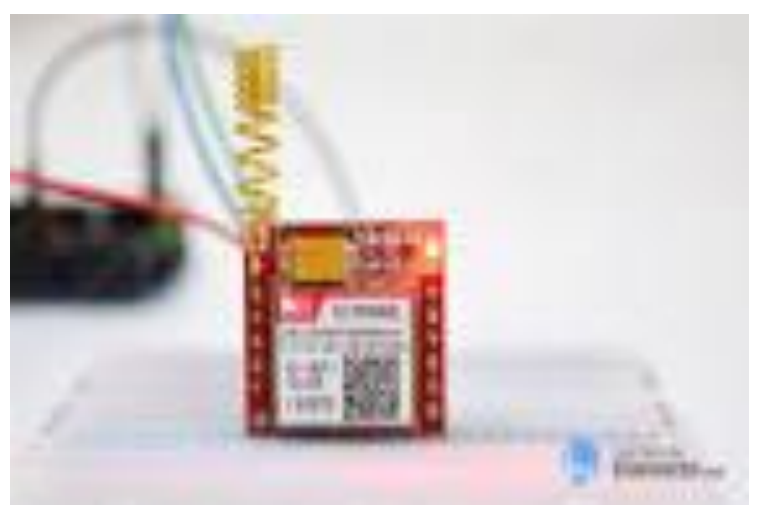

Fig. 5: GSM Module

\subsection{Wifi Module Unit}

ESP 8266 Wi-Fi module is a self contained Service Organization Ccontrol (SOC) with integrated TCP/IP Protocol that gives the microcontroller access to the Wi-Fi network which is capable of hosting an application or offloading all Wi-Fi networking functions from another application processor. This module is also used to power the device which makes it automated but its problem is the distance barrier because of the range. It is less expensive than the GSM Module due to the distance covered and low data consumption. This module has a powerful enough on board processing and storage capability which allows it to be integrated with sensors and other applications which is extremely cost effective as shown in Fig 6 .

To activate Sound using the Wi-Fi still with the first switch powered on, the mobile hotspot of the phone is powered ON and is connected to Wi-Fi module in the device for sound activation through an application known as Blynk which connects to the device through the microcontroller AT mega328 confirmed Via the Email through the OTP (One time Password). The Programming Module is as shown.

//char auth[] = "83d6e90137564dc483241c38b6971352";

SoftwareSerialEspSerial $(11,10)$; // RX, TX

char ssid[] = "Yuken CX ";

char pass[] = "bestofkings";

\#define ESP8266 BAUD 9600

ESP8266 wifi(\&EspSerial);

BlynkTimer timer; 


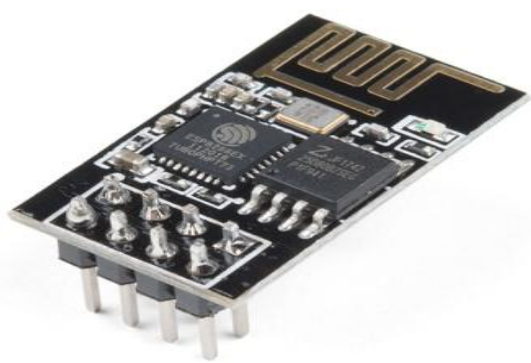

Fig. 6: ESP 8266 Wifi Module

\subsection{Water Surface Unit}

This is where the device is tested after assembly packaged into the casing. It is placed on or immerse in water so as to attract fishes and other marine animals through sounds broadcast from the device into the surrounding water. A fish pond was improvised as the water surface for which the device was tested which can also be tested on any other water surface.

\section{IMPLEMENTATION}

The device was implemented using the circuit diagram of Fig 7 and packaged after it has undergone the various test (component, functional, etc) and certified to work properly. Fig 8 and Fig 9 showed the Inner Connection and the Outer Package of the Device, respectively. The device has two switches to operate: one to power ON the device and the other is for manual operation in the case of network failure for the GSM and Wi-Fi modules.

The device is activated for Sound to attract marine organisms specifically fishes in three ways; these are through SMS (Message), Wi-Fi and manual. To activate with the SMS, the first switch is powered $\mathrm{ON}$ indicating the device is ready then the red reset button is pressed. The text message which has been programmed is then sent to the device. To activate with the $\mathrm{Wi}-\mathrm{Fi}$, the same procedure is taken only that the green reset button is pressed this time; the mobile hotspot of the phone turned $\mathrm{ON}$ and is connected to Wi-Fi module in the device. The third is the manual operation in the event of network failure for both the GSM and Wi-Fi modules; this is made possible by the use of the second switch.

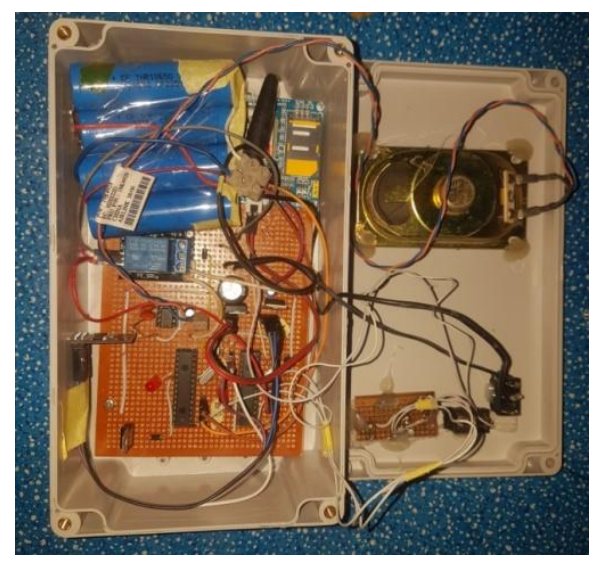

Fig. 8: Inner Connection of the Device

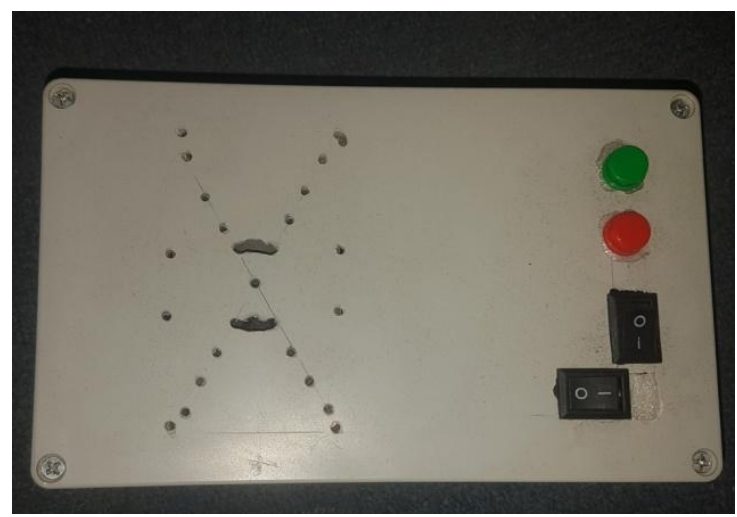

Fig. 9: Outer Package of the Device

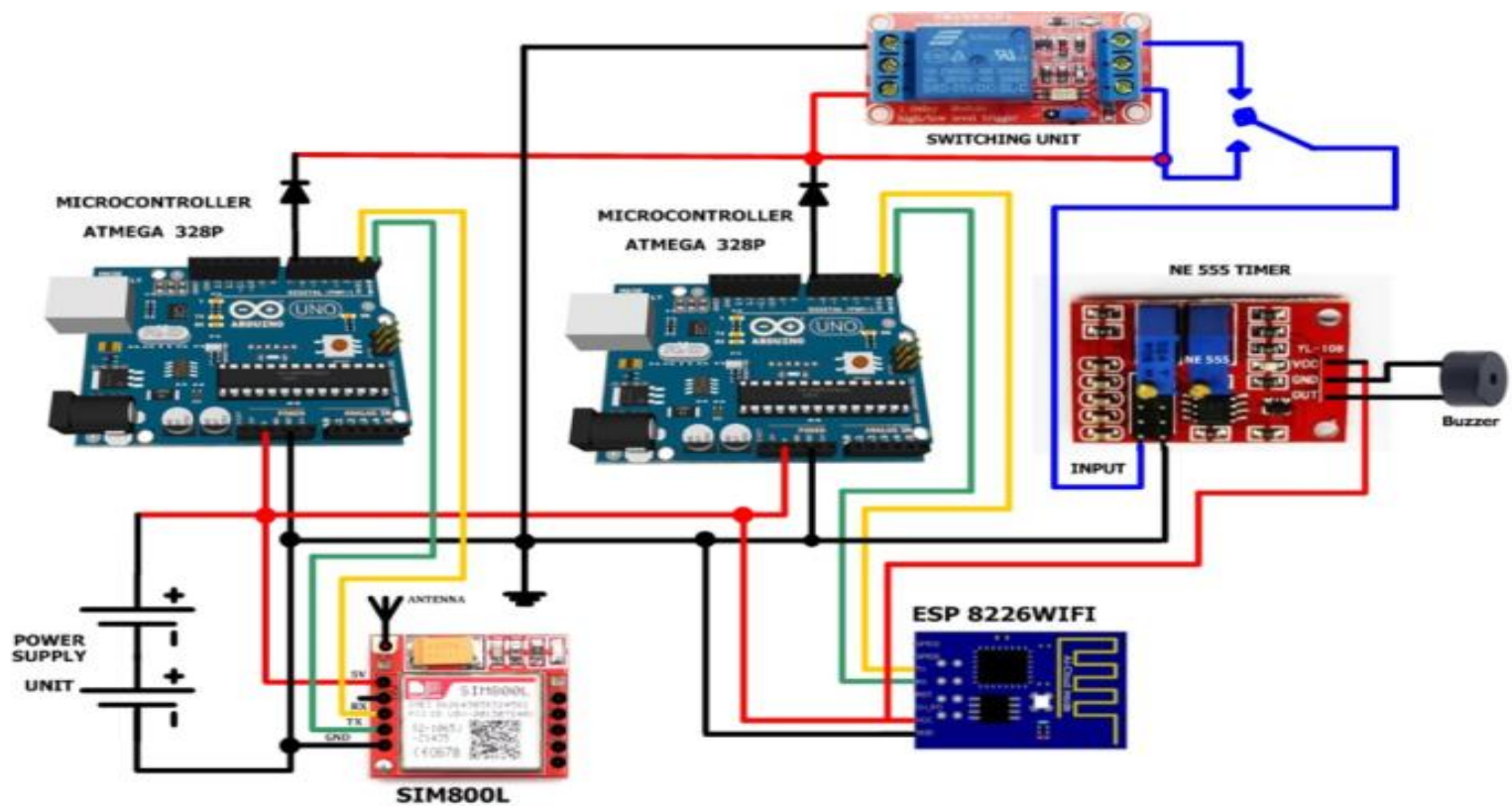

Fig. 7: Aquaculture Response Circuit 


\section{RESULTS AND DISCUSSION}

The developed Aquaculture Response device proved to be effective as it was implemented on an indigenous fish pond with significant response through the attraction of fishes at the trigger of the sound using the three activation modes. The device was sealed in a polythene bag before its immersion in the pond, Fig 10, Fig 11 and Fig 12 showed the device on water before Fish attraction, device inside water with Cat Fish, device attracting Cat Fish. The continuous sound produced by the device was able to attract a larger percentage of the fishes in the pond. It was discovered that 16 out of 18 catfish in the pond were attracted by the sound from the device, which is an $88.8 \%$ success rate.

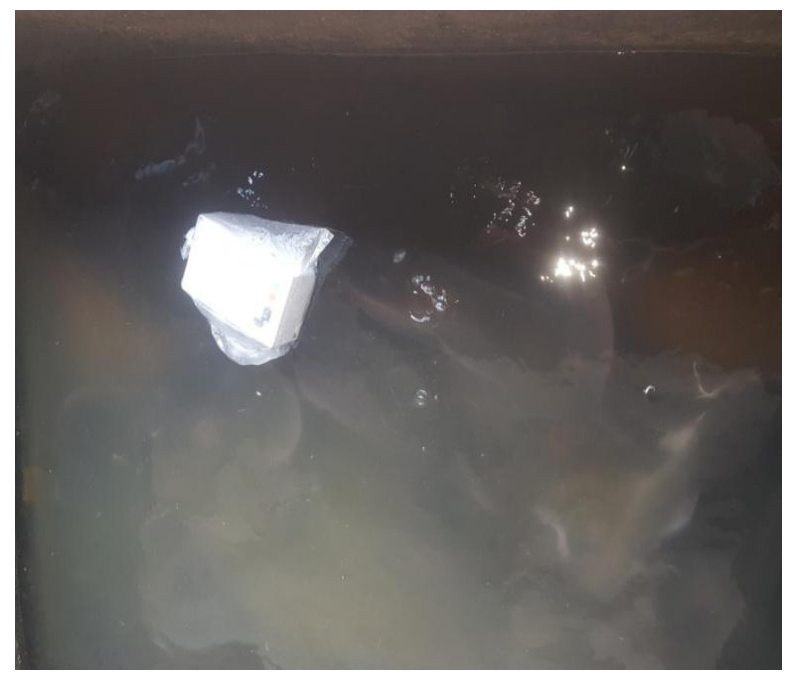

Fig 10: Device on Water before Fish Attraction

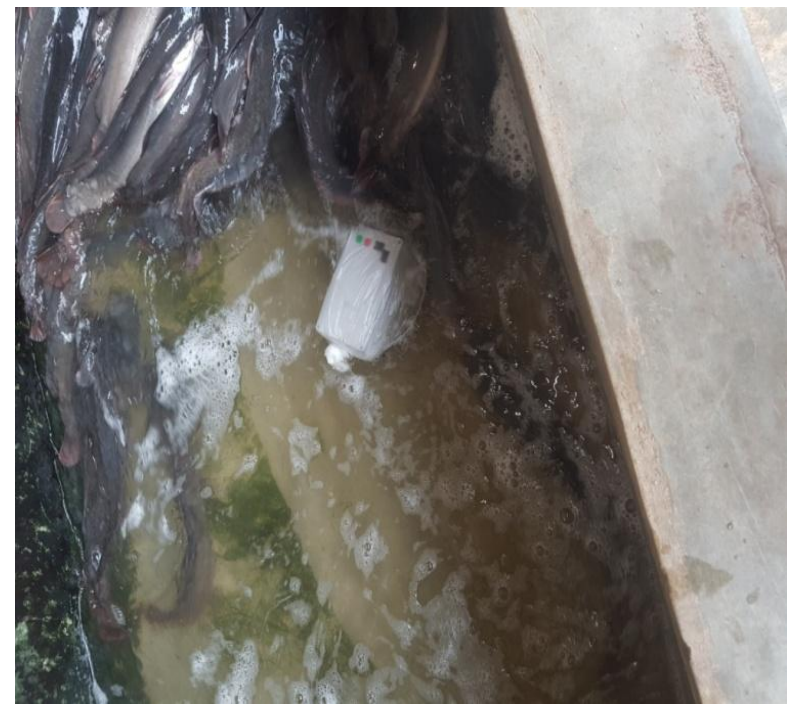

Fig 11: Device inside water with Cat Fish

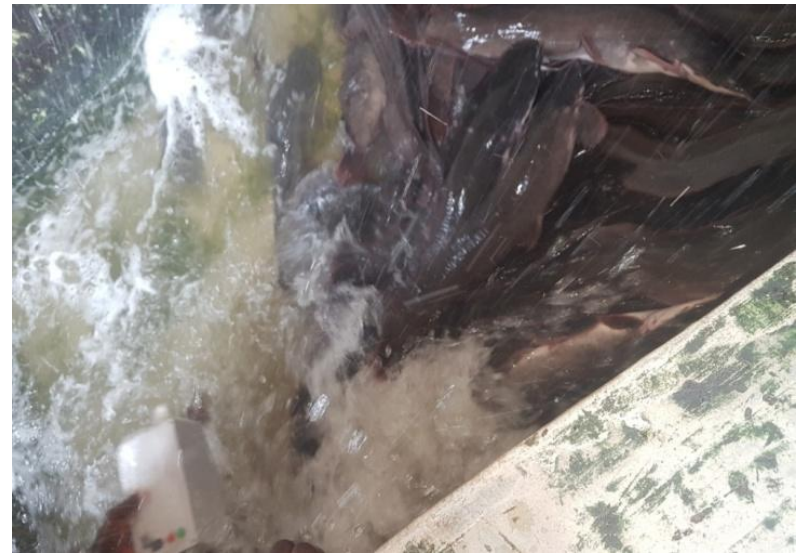

Fig 12: Device attracting Cat Fish

\section{CONCLUSION}

The aquaculture response device was designed, constructed, and implemented on a small scale Fish pond; though the implementation did not achieve $100 \%$ success but the result was appreciable as $88.8 \%$ success was recorded. All the components were locally sourced which makes it affordable and available for Fish Farmers. The three activation modes of this device also allow for the suitability of this work in an area where power supply and internet accessibility is epileptic.

\section{RECOMMENDATIONS}

This device is constructed to only attract Fish, it is recommended that the future research should be targeted towards its catch or trap, large scale production of this device to fish farmers will also go a long way to ease farmer's stress and subsequent increase in yield.

\section{REFERENCES}

[1] Au, W.W.L and Hastings, M.C (2008) Principles of Marine Bioacoustics, Springer, New york.

[2] Bregman A.S (1990). Auditory Scene Analysis: the Perpetual Organization of Sound, The MIT Press, Cambridge.

[3] Danos, J. A and Danos, J.E. (2015). Fish Call. Effects of Exposure to Pile Driving Sound on Fish Inner Ear 166(1): $352-360$

[4] Fuentes, G. S. and Hidalgo, O. L. (1989). Sonic Fishing Lure. U.S. Patent No. 4,805,339.

[5] Gerard T. and Pau 1. H. (1986). Fish attraction with Pulsed Low Frequency Sound. Canadian Journal of Fisheries and Aquatic Sciences, 43(4): 855-862.

[6] Kyo, Y. P (2007). Simplicity Source Depth Finder for Fishing. U.S. Patent Fish Detector US 7,554,884.

[7] Matthew, R. N. and Cory D. S. (2012). Non Physical Barrier to detect Fish Movement. Environmental Reviews, 20(1): 71-82.

[8] Rosana, N (2017). Determination of Sound Waves for Design of Piknet. Proceeding of Hangtuah University National Marine Seminars, Surabaya. 85(1): 19-22.

[9] Popper, A. N (2012) Effects of noise on Aquatic Life. Inner Ear and Lateral Line Psychology of Fishes. 14(8): 116-117.

[10] Popper, A. N and Plat C (1993). Inner Ear and Lateral Line. The Physiology of Fishes. $1^{\text {st }}$ Edition, CRC Press. 
International Journal of Computer Applications (0975 - 8887)

Volume 174 - No. 23, March 2021

[11] Radford A. N., Kerridge E. and Simpson S. D. (2014). Acoustic communication in a noisy world: can fish compete with anthropogenic noise, The official journal of the ISBE International Society for Behavioural Ecology. 25(5) 1022-1030.

[12] Szilagyi, F. and Hayes, S. W. (1991). Fish Caller. U.S.

\section{Patent No. 5,046,278}

[13] Danos, J. A and Danos, J. E. (2015). Fish Call. https://www.thefishcall.com.

[14] HDR， 2018， http://hdr.undp.org/en/content/nationalhuman-development-report-2018-nigeria. 